\title{
Releituras do simbólico e da Lei na teoria de gênero de Judith Butler
}

\author{
Reinterpretations of the symbolic and the Law in \\ Judith Butler's gender theory
}

\author{
André Luiz dos Santos Paiva \\ https://orcid.org/0000-0002-1887-9960 - E-mail: alz.paiva@gmail.com
}

\begin{abstract}
RESUMO
O artigo discute como os conceitos de simbólico e Lei aparecem na construção da teoria de gênero de Judith Butler. Explicita-se como a autora recorre ao conceito de proibição como marco de análise, de forma que se produz uma inflexão entre seu pensamento e a psicanálise. Além disso, se analisa como é realizada a articulação entre psiquismo e poder em Butler, momento no qual ela estabelece um diálogo com Michel Foucault. Assim, a partir de uma proposição que mescla aspectos do psiquismo com dinâmicas de funcionamento do poder, Butler realiza uma releitura da teorização lacaniana tradicional sobre o simbólico, com a finalidade de visibilizar processos de resistência que permitem a reconfiguração do simbólico e da cultura, empreendimento que pode ser aproximado ao realizado por Deleuze e Guattari, ainda que Butler recuse uma aproximação teórica com esses autores.
\end{abstract}

Palavras-chave: Teoria de gênero. Lacan. Simbólico. Resistências. Cultura.

\begin{abstract}
The article discusses how the concepts of symbolic and Law appear in the construction of Judith Butler's theory of gender. It explains how the author uses the concept of prohibition as a framework for analysis, so that an inflection between her thinking and psychoanalysis is produced. In addition, it analyzes how the articulation between the psychic and power is
\end{abstract}


carried out in Butler, when she establishes a dialogue with Michel Foucault. Thus, based on a proposition that mixes aspects of the psyche with dynamics of the functioning of power, Butler performs a re-reading of traditional Lacanian theorizing about the symbolic, with the purpose of making visible processes of resistance that allow the reconfiguration of the symbolic and of culture, an undertaking that it can be approximated to that carried out by Deleuze and Guattari, although Butler refuses a theoretical approximation with these authors.

Keywords: Gender theory. Lacan. Symbolic. Resistances. Culture.

Ao discutir as formas de funcionamento do sistema de sexo-gênero, Judith Butler (1993), frequentemente, recorre ao conceito de proibição como marco de análise. Nesse sentido, ela dialoga fortemente com discussões advindas da psicanálise, notadamente a lacaniana, para complexificar o lugar que os sujeitos e as dinâmicas sociais ocupam nos processos de proibição. A autora explicita como é operada a proibição de certos atos e práticas. Além disso, expõe como, a partir dessas limitações, pode-se pensar e intervir sobre as fronteiras a serem extrapoladas pelos processos de resistência, momento no qual dialoga com autores não advindos da psicanálise, como Michel Foucault.

Na esfera específica das sexualidades, Butler (1993) chama a atenção para a possível erotização das práticas proibidas, uma vez que, ao se proibir algo, além de fazê-lo vir a público, têm-se também o efeito de inserir o proibido enquanto potencial fonte de investimentos eróticos. Esse efeito é também encontrado no âmbito dos corpos, dado que a formação e delimitação das fronteiras corporais também se fundam numa série de proibições, e essas permitem o engendramento de um critério de inteligibilidade que acaba por ser a própria possibilidade de constituição subjetiva. Sobre essa questão, Butler avança e afirma:

Se as proibições, em certo sentido, constituem morfologias projetadas, a reformulação dos termos dessas proibições sugere a possibilidade de projeções variáveis, modos variáveis de delinear e teatralizar superfícies corporais. Essas seriam "ideias" do corpo sem as quais não poderia haver ego, nem centralização temporária da experiência. Na medida em que essas "ideias" de apoio são reguladas pela proibição e pelo sofrimento, elas podem ser entendidas como os efeitos forçados e materializados do poder regulador. Mas, precisamente porque as proibições nem sempre "funcionam", ou seja, nem sempre produzem o corpo dócil que se adapta totalmente ao ideal social, elas podem delinear superfícies corporais que não significam polaridades heterossexuais convencionais. Essas superfícies corporais variáveis ou egos corporais podem, assim, tornarem-se locais de transferência de características que não pertencem mais a nenhuma anatomia (BUTLER, 1993, p. 64) (tradução nossa ${ }^{1}$ ).

Nessa altura de seu pensamento, Butler realiza uma inflexão em direção à psicanálise. Isso ocorre pela crítica realizada pela autora acerca da polarização entre as teorias do poder e a teorias sobre o psiquismo, algo que, segundo ela, encontramos, inclusive, em Michel Foucault, autor com quem a filósofa norte-americana desenvolve uma profícua relação e que é utilizado por ela para complexificar suas leituras acerca do psiquismo (BUTLER, 1999). Para realizar essa

\footnotetext{
1 "If prohibitions in some sense constitute projected morphologies, then reworking the terms of those prohibitions suggests the possibility of variable projections, variable modes of delineating and theatricalizing body surfaces. These would be "ideas" of the body without which there could be no ego, no temporary centering of experience. To the extent that such supporting "ideas" are regulated by prohibition and pain, they can be understood as the forcible and materialized effects of regulatory power. But precisely because prohibitions do not always "work", that is, do not always produce the docile body that fully conforms to the social ideal, they may delineate body surfaces that do not signify conventional heterosexual polarities. These variable body surfaces or bodily egos may thus become sites of transfer for properties that no longer belong properly to any anatomy."
} 
espécie de integração entre as teorizações em torno do poder e as discussões acerca da formação psíquica, Butler recorre, principalmente, ao conceito de simbólico em Lacan, ainda que opere críticas e reapropriações singulares do vislumbre lacaniano sobre a formação do psiquismo humano.

Ao desenvolver sua teorização aplicada à clínica psicanalítica, Lacan desenvolveu marcos, denominados por ele de registros, que permitiram a criação de uma forma específica, ainda que em diálogo direto com o pensamento freudiano, de conceber o psiquismo humano (CLAVURIER, 2013). Esses marcos foram por ele denominados de real, imaginário e simbólico (LACAN, 1953), e eles "[...] constituem o lugar de habitação do dito, ou seja, homem enquanto ser falante: elas são as três dimensões constitutivas do espaço habitado pelo homem na condição de ser falante" (CLAVURIER, 2013, p. 129).

Assim, em Lacan (1953), encontramos uma forte conexão dos registros psíquicos com a linguagem, relação que se torna ainda mais estreita quando falamos do simbólico. Nesse sentido, o ingresso no registro simbólico se dá enquanto processo de ingresso na cultura e, consequentemente, na linguagem. Essa linguagem não é defendida pelo psicanalista enquanto natural, de forma que sequer é possível determinar em que momento ela começou, tampouco definir como as coisas se davam antes de sua emergência.

A linguagem exerce uma função que remete aos primórdios da experiência humana, sendo ela a responsável por tornar os indivíduos sujeitos, a partir do compartilhamento do que Lacan (1953) denominou de senha. Para isso, o humano deu sentido às palavras, o que foi um grande avanço no campo da linguagem, e esse sentido passou a ser compartilhado de forma a tornar possível a comunicação, uma vez que,

[...] na origem, o homem é que, com efeito, dá seu sentido à palavra [mot]. E que só as palavras [mots] depois se encontraram no comum acordo da comunicabilidade, isto é, que as mesmas palavras [mots] servem para se reconhecer a mesma coisa; é precisamente em função de relações, de uma relação de saída que possibilitou a estas pessoas serem pessoas que comuniquem (LACAN, 1953, s/p).

A partir dessa relação com as palavras, logo, relação discursiva, é possível falar de um registro simbólico propriamente dito, ainda que esse não se restrinja às expressões faladas ou escritas da subjetividade humana. É através do registro simbólico que o humano pode ser reconhecido e assim reconhecer-se enquanto um eu, sendo no campo simbólico que o sujeito encontra pertencimento a partir da formação de uma unidade. Essa unidade, ainda que não permanente, projeta-se sucessivamente enquanto sequência de unidades. Essa relação entre constituição do eu e temporalidade no registro simbólico é resumida da seguinte forma:

[...] logo que se trata do simbólico, isto é, aquilo em que o sujeito se dirige numa relação propriamente humana, logo que se trata de um registro do "eu" [je], aquilo em que o sujeito se dirige em "eu quero, eu amo...", há sempre algo, literalmente falado, problemático, isto é, que há aí um elemento temporal muito importante a se considerar (LACAN, 1953, s/p).

É a partir dessa concepção temporalizada e radicalmente conectada ao campo da cultura e da linguagem que Butler realiza a aproximação de sua teorização acerca das relações de sexo-gênero com o pensamento lacaniano. No entanto, a autora identifica uma espécie de desvio no pensamento de Lacan, pois, ainda que ele coloque o registro simbólico enquanto algo construído na experiência humana, acaba por reificar esse registro de maneira a tornar inviável a experiência humana fora dos marcos da subjetivação estabelecida pelo funcionamento simbólico (BUTLER, 1997; 1993). 
Butler (1993) realiza a conexão entre o registro simbólico e o poder, de forma que, ao se pensar o simbólico, se estaria frente a um marco de regulação que estabelece um ideal de funcionamento psíquico. Ao questionar o caráter rígido que a psicanálise impõe ao registro simbólico, Butler opera um movimento que permite a reformulação das leis simbólicas, num sentido destas perderem seu estatuto de adesão necessária. Assim, o que a filósofa propõe é a possibilidade de ressignificação da esfera simbólica, o que passaria pela adesão radical à ideia de temporalidade que o próprio Lacan havia destacado quando da delimitação dos registros psíquicos. Isso permitiria a retirada do simbólico de um lugar estruturado de forma semipermanente e o colocaria numa dinâmica mais flexível do ponto de vista psíquico, bem como e por consequência, no que tange às dinâmicas sociais e políticas (BUTLER, 1993).

Para que essa reelaboração temporal seja possível, uma outra crítica deve ser exercitada. Ela se refere ao questionamento da autoridade que emerge através da Lei tal qual encontrada na psicanálise lacaniana. Nesse sentido, a Lei passaria a ser vista como mais uma ficção reguladora que se pretende universal e necessária, leitura que acompanha o que Foucault (2015, 1988) denominou de poder regulatório, a partir do qual normas são estabelecidas de forma auto justificada com a finalidade de padronização das experiências subjetivas e sociais, seja de forma jurídica, seja de forma produtiva.

Butler (1993) chama a atenção acerca desse funcionamento da Lei, mostrando como ela estrutura no processo de produção de subjetividades um excesso de poder creditado ao simbólico que oculta sua instância citacional pela qual se consolida. Torna-se, a partir disso, indispensável analisar a partir de que mecanismos o simbólico é investido de poder, num sentido desse impor uma sobreposição do simbólico em relação ao imaginário, registro que, por sua capacidade criativa, tem a possibilidade de colocar em xeque as leis simbólicas. Assim, as identificações realizadas no registro imaginário são duplamente capturadas pelo registro simbólico. Primeiro, porque a identificação imaginária é previamente investida pela lei simbólica, que é estabelecida como o parâmetro a priori; segundo, pela Lei não poder ser questionada pelo imaginário, dado ser instituída enquanto autoridade que precede qualquer possibilidade de ingresso na cultura e na linguagem.

É exatamente nesse aspecto apriorístico do simbólico que Butler (1993) encontra a brecha que permite a refutação do caráter de lugar de estabelecimento de lei absoluta para esse registro. Para ela, a autoridade da Lei é constituída através de recursos citacionais que, em sua repetição ocultada, engendra o caráter inquestionável da ordem simbólica. Essa espécie de ameaça em torno da impossibilidade de constituição subjetiva fora dos marcos simbólicos instituídos acaba por denunciar a arbitrariedade de seu estabelecimento, de forma que, para Butler, não há uma posição anterior privilegiada que legisle sem possibilidade de questionamento acerca da formação psíquica e processos de subjetivação, mas, ao contrário disso, o que ocorre é a reificação de uma ficção reguladora.

Com essa discussão, Butler $(1997,1993)$ explicita o caráter disciplinar que o conceito de simbólico e de Lei operam no que tange a formação subjetiva de forma geral, bem como aos aspectos de sexo-gênero que Ihe concernem. Assim, a ideia de psiquismo acaba por operar em marco semelhante a ideia de alma, enquanto instância que baseia metafisicamente as experiências dos indivíduos ao se instituir como marco inicial e sobre o qual a origem ou construção não se questiona (NAVARRO, 2008). Nota-se a partir disso o caráter problemático de se tomar imperativos culturais, como o simbólico, enquanto verdades inescapáveis, ainda que esses não devam, por isso, ser eliminados do horizonte de análise, uma vez que Butler $(1997,1993)$ não recusa a existência do registro simbólico, mas sim seu caráter rígido e de difícil mutabilidade. 
O que a autora propõe é uma leitura que leve em consideração o simbólico a partir do cruzamento com a ideia de disciplina, de forma a complexificar ambos os conceitos, relação sobre a qual ela afirma:

Nesse sentido, tenho problemas com a perspectiva da hipótese repressiva em Foucault como meramente uma instância do poder jurídico, e defendo que essa concepção não trata das maneiras pelas quais a "repressão" opera como uma modalidade de poder produtivo. Pode haver uma maneira de sujeitar a psicanálise a uma redescrição foucaultiana, mesmo que o próprio Foucault tenha recusado essa possibilidade. Este texto aceita como ponto de partida a noção de Foucault de que o poder regulador produz os sujeitos que controla, que o poder não é apenas imposto externamente, mas funciona como o meio regulatório e normativo pelo qual os sujeitos são formados. O retorno à psicanálise, então, é guiado pela questão de como certas normas reguladoras formam um sujeito "sexuado" em termos que estabelecem a indistinguibilidade da formação psíquica e corporal. Onde algumas perspectivas psicanalíticas localizam a constituição do "sexo" em um momento de desenvolvimento ou como um efeito de uma estrutura simbólica quase permanente, eu entendo esse efeito constitutivo do poder regulador como reiterado e reiterável. Para essa compreensão do poder como uma produção restrita e reiterativa, é crucial acrescentar que o poder também funciona através da exclusão do efeito, da produção de um "fora", um domínio do inabitável e de ininteligibilidade que limita o domínio de efeitos inteligíveis (BUTLER, 1993, p. 22) (tradução nossa²).

É a partir da proposição de uma leitura que mescla os aspectos do psiquismo com as dinâmicas de funcionamento do poder que Butler abre espaço em sua teorização para os processos de resistência. O que é proposto nessa altura do pensamento de Butler é que o registro do real acaba por impor resistências ao processo de ingresso no simbólico, de maneira que é possível pensar o real enquanto campo que possibilita ao psíquico uma experiência não necessariamente atrelada ao mimetismo estrito que encontramos no registro simbólico. Essa concepção de real é a mesma encontrada em Lacan (1953), no entanto, para o autor, mantêm-se a ideia de que é indispensável que o real se dobre ao simbólico para que o sujeito seja viável, o que acaba por legitimar o simbólico como marco cultural e linguístico indispensável; enquanto que, para Butler (1993), a questão que emerge dessa relação é a de como politizar essa relação entre linguagem e real, de forma a se apropriar do espaço de resistência psíquica enquanto lugar de resistências políticas.

Para operar esse movimento, Butler (1993) questiona a prevalência do registro simbólico no que tange à autoridade de produzir o interior e exterior do que conta enquanto vida psíquica legítima através dos processos de forclusão. Com isso, Butler defende que, apesar de todas as formações de linguagem terem a necessidade de operar por exclusões, isso não quer dizer que todas as exclusões sejam equivalentes umas às outras. Para ela, "o que é necessário é uma maneira de avaliar politicamente como a produção de ininteligibilidade cultural é mobilizada de maneira variável para regular o campo político, ou seja, quem contará como um 'sujeito', e quem

\footnotetext{
2 "In this sense, I take issue with Foucault's account of the repressive hypothesis as merely an instance of juridical power and argue that such an account does not address the ways in which "repression" operates as a modality of productive power. There may be a way to subject psychoanalysis to a Foucaultian redescription even as Foucault himself refused that possibility. This text accepts as a point of departure Foucault's notion that regulatory power produces the subjects it controls, that power is not only imposed externally, but works as the regulatory and normative means by which subjects are formed. The return to psychoanalysis, then, is guided by the question of how certain regulatory norms form a "sexed" subject in terms that establish the indistinguishability of psychic and bodily formation. And where some psychoanalytic perspectives locate the constitution of "sex" at a developmental moment or as an effect of a quasi-permanent symbolic structure, I understand this constituting effect of regulatory power as reiterated and reiterable. To this understanding of power as a constrained and reiterative production it is crucial to add that power also works through the foreclosure of effect, the production of an "outside", a domain of unlivability and unintelligibly that bounds the domain of intelligible effects."
} 
será obrigado a não contar" (BUTLER, 1993, p. 207) (tradução nossa3). Nesse sentido, estabelecer o registro do real enquanto um exterior impossível acaba por inviabilizar experiências não enquadráveis de forma inquestionável no registro simbólico, o que acaba por confirmar a hipótese da autora de que as dinâmicas psíquicas se relacionam com relações de poder contingentes que permitem ou não o reconhecimento das variadas experiências humanas.

A complexa dinâmica entre o real e o simbólico analisada por Butler (1993) encontra-se diretamente relacionada à sua apropriação de que o inconsciente, tal qual pensado por Freud e Lacan, também se configura enquanto uma experiência de resistência. $O$ que se encontra nas dinâmicas inconscientes são, muito comumente, processos de resistência à normalização que são impostas pelas necessidades de conformidade com o campo da cultura, logo, com o registro simbólico. A resistência opera devido ao fato de que, ainda que o sujeito precise se adequar às normas para ser reconhecido enquanto tal, a experiência psíquica nunca se restringe ao restrito da cultura, uma vez que há sempre em operação os registros do real e do imaginário (BUTLER, 1997).

No entanto, a própria experiência inconsciente não passa sem o escrutínio da crítica. Assim, mesmo quando se pensa o inconsciente enquanto uma instância que opera a partir das resistências, Butler (1997) não deixa de tensionar a discussão apontando que não há nada que permita defender que o inconsciente não é ele mesmo atravessado e estruturado por relações de poder engendradas no campo da cultura. Nesse sentido, fica explícito que a resistência inconsciente não necessariamente será produtiva quando se pensa em termos de resistências políticas. O que deve ser depreendido das análises de Butler acerca do inconsciente não é que esse seria o lugar privilegiado para o questionamento da ordem simbólica, mas apenas que ele é o lugar possível para a ocorrência desse processo, uma vez que denuncia a possibilidade de falhas na constituição subjetiva, podendo abrir um campo de questionamento e transformação política que se arrogue a possibilidade de não reificar o registro simbólico e, com isso, permitir campos de reconhecimento mais amplos.

As resistências do inconsciente ao simbólico permitem a rearticulação dos termos desse último, dado denunciarem os esforços necessários para a legitimação da cultura e da linguagem, o que permite a Butler a sua articulação com a concepção de poder encontrada em Michel Foucault, uma vez que,

A noção de "simbólico" não trata da multiplicidade de vetores de poder sobre os quais Foucault insiste, pois o poder em Foucault não consiste apenas na elaboração reiterada de normas ou demandas interpelantes, mas é formativo ou produtivo, maleável, múltiplo, proliferativo e conflituoso. Além disso, em suas ressignificações, a própria lei é transmutada naquilo à que se opõe e excede seus propósitos originais. Nesse sentido, o discurso disciplinar não constitui unilateralmente um sujeito em Foucault, ou melhor, se o fizer, constitui simultaneamente a condição para a desconstituição do sujeito (BUTLER, 1997, p. 99) (tradução nossa $a^{4}$.

No campo psicanalítico, ocorre o ocultamento dessa relação intrínseca entre psiquismo e relações de poder, exatamente por, na esfera das relações de sexo-gênero, haver a necessidade de manutenção da ideia de diferença sexual que sustenta a base da teoria e clínica psica-

\footnotetext{
3 "What is needed is a way to assess politically how the production of cultural unintelligibility is mobilized variably to regulate the political field, i.e., who will count as a 'subject', who will be required not to count".

4 "The notion of "the symbolic" does not address the multiplicity of power vectors upon which Foucault insists, for power in Foucault not only consists in the reiterated elaboration of norms or interpellating demands, but is formative or productive, malleable, multiple, proliferative, and conflictual. Moreover, in its resignifications, the law itself is transmuted into that which opposes and exceeds its original purposes. In this sense, disciplinary discourse does not unilaterally constitute a subject in Foucault, or rather, if it does, it simultaneously constitutes the condition for the subject's de-constitution".
} 
nalítica: o complexo de Édipo. Para Butler (1993), o tabu do incesto que sustenta a triangulação edípica da formação psíquica é, antes disso, um tabu sobre a homossexualidade. Isso porque durante a passagem pelo Édipo, os indivíduos necessariamente passarão por uma identificação estruturante com o genitor do gênero oposto ao que foi designado, o que sustenta a partição binária entre os sexos e, consequentemente, entre os gêneros.

O que ocorre no processo de passagem pelo Édipo é a conexão simultânea entre a anatomia dos corpos e a linguagem, de forma que se torna impossível pensar uma sem a outra, o que acaba por estabelecer uma relação tautológica. Dessa primeira conexão, advém a impossibilidade encontrada em psicanálise de emergência do sujeito sem o marco da diferença sexual pensada de forma binária, o que tem por consequência a possível imposição da heterossexualidade enquanto norma a partir da qual todas as expressões de sexualidades passam a ser medidas (BUTLER, 1993).

O que Butler $(1993,1997)$ explicita em sua crítica ao conceito de diferença sexual no que concerne à psicanálise é que essa acaba por limitar as possibilidades de resistências que o processo de formação psíquica pode ter, uma vez que, ao invés de investir nesse âmbito enquanto potencialmente disruptivo, o pensamento psicanalítico tradicional acaba por utilizá-lo enquanto instrumento de normalização reiterativa do poder simbólico de estruturar dinâmicas sexistas e homofóbicas. Nesse sentido, o simbólico antes de ser pensado enquanto instância estabilizadora do psiquismo que permite aos indivíduos ingressarem na cultura, deve ser compreendido

[...] como a dimensão normativa da constituição do sujeito sexuado na linguagem. Consiste em uma série de demandas, tabus, sanções, injunções, proibições, idealizações impossíveis e ameaças - atos de fala performativos, por assim dizer, que exercem o poder de produzir o campo de sujeitos sexuados culturalmente viáveis: atos performativos, em outras palavras, com o poder de produzir ou materializar efeitos subjetivos. Mas que configuração cultural de poder organiza essas operações normativas e produtivas da constituição do sujeito? (BUTLER, 1993, p. 106) (tradução nossa $a^{5}$.

O que ocorre com a crítica que Butler realiza do conceito de simbólico e suas relações com determinadas distribuições de poder dialoga com sua defesa de que a formação do psiquismo e as dinâmicas do desejo nunca são completamente determinadas por uma instância, a exemplo do simbólico, mas, ao contrário

[...] se caracteriza pelo deslocamento, pode exceder a regulação, assumir novas formas em resposta à regulação, até transformar-se e torná-la atrativa. Nesse sentido, a sexualidade nunca é totalmente redutível ao "efeito" desta ou daquela operação do poder regulador (BUTLER, 2004, p. 15) (tradução nossa ${ }^{6}$ ).

Butler parece operar movimento semelhante ao realizado por Deleuze e Guattari (2011), num sentido de questionamento das intenções universalizantes e deterministas das concepções de inconsciente, complexo de Édipo e registros simbólicos. Deleuze e Guattari (2011) propõem um funcionamento produtivo do desejo, em oposição ao desejo enquanto falta encontrado na psicanálise de acordo com esses autores. Nesse sentido, sem negar de forma absoluta

\footnotetext{
5 "[...] as the normative dimension of the constitution of the sexed subject within language. It consists in a series of demands, taboos, sanctions, injunctions, prohibitions, impossible idealizations, and threats - performative speech acts, as it were, that wield the power to produce the field of culturally viable sexual subjects: performative acts, in other words, with the power to produce or materialize subjectivating effects".

6 "[...] it is characterized by displacement, it can exceed regulation, take on new forms in response to regulation, even turn around and make it sexy. In this sense, sexuality is never fully reducible to the 'effect' of this or that operation of regulatory power".
} 
a formação do sujeito a partir do Édipo, o que eles propõem com sua esquizoanálise é que Édipo seria uma forma de produção psíquica, a predominante na organização social capitalista, mas não a única.

A impossibilidade de universalização do Édipo em qualquer tempo e cultura é, para a perspectiva esquizoanalítica, a prova de que ele é uma forma de postura em funcionamento de dinâmicas de repressão. Para Deleuze e Guattari (2011) "acredita-se muitas vezes que Édipo é fácil, que é dado. Mas não é assim: Édipo supõe uma fantástica repressão das máquinas desejantes" (p. 13), de forma que se torna indispensável evidenciar o caráter produtivo do desejo, e não uma dinâmica de falta, para que seja possível a ruptura com a triangulação edípica que engendra sujeitos predominantemente neuróticos.

Baremblitt (2010) defende que essa concepção de desejo permite a Deleuze e Guattari o estabelecimento de uma proposição acerca do psíquico sobretudo ética. Isso ocorre porque, ao introduzir o caráter produtivo do desejo em sua concepção de psiquismo, os autores permitem o ingresso do desejo na materialidade produtiva da realidade, uma vez que é rompida a cisão entre psiquismo e realidade social através da potência criativa do que eles denominaram de máquinas desejantes. Assim, “há em toda parte máquinas produtoras ou desejantes, as máquinas esquizofrênicas, toda a vida genérica: eu e não-eu, exterior e interior, nada mais querem dizer" (BAREMBLITT, 2010, p. 12).

Essa forma de funcionamento do desejo permite que diversos fluxos encontrem-se e desencontrem-se sem qualquer compromisso necessário com uma estrutura, seja ela social ou psíquica, dado que até mesmo essa distinção torna-se inviável (DELEUZE; GUATTARI, 2011). Isso permite à esquizoanálise a defesa da existência de infinitas maneiras de funcionamento inconscientes, que podem tanto direcionar-se para a produção de subjetividades sujeitadas, como para formas de subjetivação libertária (BAREMBLITT, 2010).

Apesar dos vários aspectos que aproximam o pensamento de Butler do de Deleuze e Guattari, a filósofa opta por não estabelecer um diálogo mais profícuo com esses autores. A crítica realizada por Butler localiza-se na concepção de desejo enquanto falta que é defendida pelos esquizoanalistas, conceito acerca do qual a autora tece críticas por preferir compreender a concepção de desejo em psicanálise enquanto baseada na negatividade. Sobre isso ela afirma:

A psicanálise parece centrada na questão da falta para Deleuze, mas eu tendo a centrar-me no problema da negatividade. Uma razão pela qual me opus a Deleuze é que não encontrei nenhum registro negativo no seu trabalho, e temi que ele estivesse propondo uma defesa maníaca contra a negatividade (BUTLER, 2004, p. 198) (tradução nossa7).

A despeito dessa divergência, persistem os pontos de aproximação entre a leitura acerca da formação psíquica nesses autores. Eles consistem numa concepção que não permite a desvinculação entre a produção desejante e a produção da realidade, bem como numa recusa de pensar o Édipo enquanto momento estruturante universal e percebê-lo enquanto uma forma totalizante de produção psíquica.

Esses pressupostos permitem a Butler (1993) realizar importantes questionamentos acerca da categoria da diferença sexual, e também permitem a Deleuze e Guattari (2011) afirmarem que, no que tange aos gêneros e sexualidades, encontramos na produção desejante

\footnotetext{
7 "Psychoanalysis seems centered on the problem of the lack for Deleuze, but I tend to center on the problem of negativity. One reason I have opposed Deleuze is that I find no registration of the negative in his work, and I feared that he was proposing a manic defense against negativity".
} 
[...] uma transexualidade microscópica em toda parte, que faz com que a mulher contenha tantos homens quanto o homem, e o homem mulheres, capazes de entrar, uns com os outros, umas com as outras, em relações de produção de desejo que subvertem a ordem estatística dos sexos (DELEUZE; GUATTARI, 2011, p. 390).

Butler, por seu turno, opta intencionalmente por manter o pensamento de Deleuze e Guattari distanciado de sua teorização, aproximando-se de Foucault para justificar seus questionamentos acerca do lugar que o simbólico ocupa em psicanálise e das relações paradoxais que suas críticas explicitam. Nesse sentido, ela chama a atenção para o fato de que, de um lado, não é possível viver fora de normas de reconhecimento e, por outro, essas normas podem, muitas vezes, produzir sofrimento a diversos sujeitos. É por isso que Butler $(1993,1997)$ explicita o caráter político das dinâmicas de reconhecimento, sendo necessário o vislumbre das hierarquias que essas podem engendrar com a finalidade de modificação de suas estruturações de poder, o que deve passar, necessariamente, por modificações no registro simbólico da realidade.

\section{Referências}

BAREMBLITT, Gregorio. Introdução à Esquizoanálise. 3a ed. Belo Horizonte: Instituto Félix Guattari, 2010.

BUTLER, Judith. Bodies that matter: on the discursive limits of "sex". Nova lorque; Londres: Routledge, 1993.

BUTLER, Judith. Gender trouble: feminism and the subversion of identity. 2a ed. New York, London: Routledge, 1999.

BUTLER, Judith. The Psychic Life of Power: Theories in Subjection. Califórnia: Stanford University Press, 1997.

BUTLER, Judith. Undoing gender. New York, London: Routledge, 2004.

CLAVURIER, Vincent. Real, simbólico, imaginário: da referência ao nó. Estudos de Psicanálise, Rio de Janeiro, n. 39, p. 125-136, 2013.

DELEUZE, Gilles; GUATTARI, Félix. O anti-Édipo: capitalismo e esquizofrenia 1. 2a ed. São Paulo: Ed. 34, 2011.

FOUCAULT, Michel. A sociedade punitiva: curso no Collège de France (1972-1973). São Paulo: Editora WMF Martins Fontes, 2015.

FOUCAULT, Michel. História da sexualidade I. A vontade de saber. Rio de Janeiro: Edições Graal, 1988.

LACAN, Jacques. O simbólico, o imaginário e o real: conferência de 8 de julho de 1953 na Sociedade Francesa de Psicanálise [online]. 1953. Disponível em: http://psicoanalisis.org/lacan/rsi-53.htm. Acesso em: 21.jul.2021.

NAVARRO, Pablo Pérez. Del texto al sexo: Judith Butler y la performatividad. Espanha: Editorial Egales, 2008 (Arquivo Kindle). 


\section{Sobre o autor}

\section{André Luiz dos Santos Paiva}

Doutor em Filosofia pela Universidade Federal do Rio Grande do Norte (UFRN). Bolsista CAPES/BRASIL de pós-doutorado no Programa de Pós-graduação em Educação Contemporânea (PPGEduC) da Universidade Federal de Pernambuco (UFPE), Centro Acadêmico do Agreste.

Recebido em: 02.08.2021.

Received: 02.08.2021.

Aprovado em: 30.09.2021.

Approved: 30.09.2021. 